\title{
Recent Advances in Molecular Genetic Linkage Maps of Cultivated Peanut
}

\author{
Baozhu Guo ${ }^{*}$, Manish K. Pandey2,3, Guohao $\mathrm{He}^{4}$, Xinyou Zhang 5 , Boshou Liao ${ }^{6}$, Albert Culbreath2, \\ Rajeev K. Varshney ${ }^{3}$, Victor Nwosu', Richard F. Wilson ${ }^{8}$, and H. Thomas Stalker ${ }^{9}$
}

\begin{abstract}
The competitiveness of peanuts in domestic and global markets has been threatened by losses in productivity and quality that are attributed to diseases, pests, environmental stresses and allergy or food safety issues. Narrow genetic diversity and a deficiency of polymorphic DNA markers severely hindered construction of dense genetic maps and quantitative trait loci (QTL) mapping in order to deploy linked markers in marker-assisted peanut improvement. The U.S. Peanut Genome Initiative (PGI) was launched in 2004, and expanded to a global effort in 2006 to address these issues through coordination of international efforts in genome research beginning with molecular marker development and improvement of map resolution and coverage. Ultimately, a peanut genome sequencing project was launched in 2012 by the Peanut Genome Consortium (PGC). We reviewed the progress for accelerated development of peanut genomic resources in peanut, such as generation of expressed sequenced tags (ESTs) $(252,832$ ESTs as December 2012 in the public NCBI EST database), development of molecular markers (over 15,518 SSRs), and construction of peanut genetic linkage maps, in particular for cultivated peanut. Several consensus genetic maps have been constructed, and there are examples of recent international efforts to develop high density maps. An international reference consensus genetic map was developed recently with 897 marker loci based on 11 published mapping populations. Furthermore, a high-density integrated consensus map of cultivated peanut and wild diploid relatives also has been developed, which was enriched further with 3693 marker loci on a single map by adding
\end{abstract}

\footnotetext{
${ }^{1}$ USDA- Agricultural Research Service, Crop Protection and Management Research Unit, Tifton, GA 31793.

${ }^{2}$ Department of Plant Pathology, University of Georgia, Athens, GA 30602.

${ }^{3}$ International Crops Research Institute for the Semi-Arid Tropics (ICRISAT), Hyderabad 502324, India.

${ }^{4}$ Department of Agricultural and Environmental Sciences, Tuskegee University, Tuskegee, AL 36088.

${ }^{5}$ Henan Academy of Agricultural Sciences, Zhengzhou 450002, China.

${ }^{6}$ Oil Crops Research Institute, Chinese Academy of Agricultural Sciences, Wuhan, China.

${ }^{7}$ Plant Science Program, Global Chocolate Science \& Technology, Mars Chocolate North America, Hackettstown, NJ 07840.

${ }^{8}$ Oilseeds \& Bioscience Consulting, 5517 Hickory Leaf Drive, Raleigh, NC 27606.

${ }^{9}$ Department of Crop Science, North Carolina State University, Raleigh, NC 27695.

*Corresponding author (e-mail: Baozhu.Guo@ars.usda.gov )
}

information from five new genetic mapping populations to the published reference consensus map.

Key Words: Arachis hypogaea, Arachis species, genomics, genetic maps, molecular markers, molecular breeding, Peanut Genome Consortium (PGC).

The world's population is predicted to reach nine billion by 2050 (Nature Editorial, 2010), which means greater demand for food, hence, a continuing need to produce improved cultivars of crop plants. Advances in food production will require greater efforts in agricultural research to increase crop yield with improved genetics for plant protection from biotic and abiotic stresses. Agricultural biotechnology is one tool that holds great promise for sustainability of agricultural production and feeding an ever increasing population.

Peanut (Arachis hypogaea L.), or groundnut, is one of the major economically important legumes that is cultivated worldwide for its ability to grow in semi-arid environments with relatively low inputs of chemical fertilizers. On a global basis, peanut also is a major source of protein and vegetable oil for human nutrition, containing about $28 \%$ protein, $50 \%$ oil and $18 \%$ carbohydrates. Peanut is cultivated in more than 100 countries in Asia, Africa and the Americas, grown mostly by resource-limited farmers of the semi-arid regions. India and China together produce almost twothirds of the world's peanuts, and the U.S. produces about 6\% (Guo et al., 2012a). Nearly two-thirds of global production is crushed for oil and the remaining third is consumed as food. Peanut plays important roles in food and nutritional security along with improving the livelihood of resource-poor farmers. Peanut production has a significant role in sustainable agriculture, global food security and nutrition, fuel and energy, and enhanced agricultural productivity.

Genetics and genomics have substantial potential to enhance sustainable peanut production. The major contribution of these technologies for peanut will likely be improved disease resistance, oil quality, and enhanced productivity. Those attributes may be achieved more effectively through 
genomic biotechnology to utilize the genetic resources preserved in germplasm collections for maximizing the genetic potential in plant breeding and genetics programs. Superior varieties will maximize desirable genetic traits and provide growers with cultivars that are locally adapted and highly productive. Genomics involves the study of the complete genetic makeup of plants, through mapping, sequencing, and functional studies to identify genes that regulate, control and modify trait expression. Together plant breeding, genetics, and genomics are powerful approaches to enhance sustainability of agriculture. However, genomic research in peanut lags behind that of other crops due to the shortage of essential genomic infrastructure, tools, and resources. In addition, the cultivated peanut is an allotetraploid with a large genome size, which greatly complicates interpretation of genomic data because of genomes duplication.

Recognizing the challenges and importance of this crop, the peanut research community established the Peanut Genomics Initiative (PGI). This review focuses on updates and accomplishments of the PGI in three areas: (1) brief chronology of recent efforts in peanut genomics; (2) recent developments in molecular markers; and (3) recent advances in genetic linkage maps in diploid wild relatives and cultivated peanut.

\section{Brief History of the Peanut Genome Initiative}

In the light of the challenges and opportunities facing cool and warm season legume crops, the international research community has cooperated to develop new genomic technologies for legume crop improvement. These efforts were initiated at a meeting at Hunt Valley, MD on 30-31 July 2001. Twenty-six legume scientists with knowledge of structural and functional genomics, DNA markers, transformation, bioinformatics, and legume crop improvement participated in a workshop hosted by the United Soybean Board, the National Peanut Foundation, the USA Dry Pea and Lentil Council, and the USDA-ARS to develop a strategy to advance genomics research across five economically important legume species. The group of scientists published the U.S. Legume Crops Genomics White Paper (Boerma et al., 2001) that outlined six areas where progress was needed across all species, including: (i) genome sequencing of strategic legume species, (ii) physical map development and refinement, (iii) functional analysis, (iv) development of DNA markers for comparative mapping and breeding, (v) characterization and utilization of legume biodiversity, and (vi) development of legume data resources. This meeting was followed by a workshop in Santa Fe, NM, in 2003, where nearly 50 legume researchers and funding agency representatives met in Santa Fe, NM, to develop a plan for cross-legume genomics research and to develop an action plan for legume research (Gepts et al., 2005). The peanut scientific community participated in both workshops. These scientists published the status of genomic resources for each legume crop, including peanut, in the book, Legume Crop Genomics (Wilson et al., 2004) under the auspices of the U.S. Legume Crop Genome Initiative (LCGI).

On 22-23 March, 2004, U.S. and international peanut scientists participated in a workshop hosted by the Peanut Foundation/American Peanut Council in Atlanta, GA (Fig. 1). A National Strategic Plan for the Peanut Genome Initiative (Wilson, 2006b) was developed that outlined six objectives for the years 2004-2008: (1) improve the utility of genetic tools for peanut genomic research and develop useful molecular markers and genetic maps for peanut, (2) improve the efficacy of technology for gene manipulation in genomes and develop useful transformation methods for functional genomic research in peanut, (3) develop a framework for assembling the peanut genetic blueprint and locate abundant and rarely expressed genes, using genetic and physical approaches to integrate diverse data types, (4) improve knowledge of gene identification and regulation, (5) provide bioinformatics management of peanut biological information resources, and (6) determine the allergenic potential of peanut proteins. An action plan summarized in the white paper National Program Action Plan for the Peanut Genome Initiative soon followed (Wilson, 2006a); and in 2006 an assessment of costs associated with genomic research were presented in the Biotech Peanut White Paper "Benefits and Issues" (Valentine et al., 2006).

In 2006, the PGI sought to expand its mission through outreach to the international peanut research community. The foundation for this effort was established in November 2006 in Guangzhou, China at the International Conference on Aflatoxin Management and Genomics where delegates from nine nations voted to maintain an open dialog to explore opportunities for cooperative research, and to take steps toward achieving that goal with annual meetings. A PGI proposal was accepted to host the second conference of the international peanut research community on 24-26 October 2007 in Atlanta, GA. This meeting, Advances in Arachis through Genomics \& Biotechnology: An International Strategic Planning Workshop, was another step 


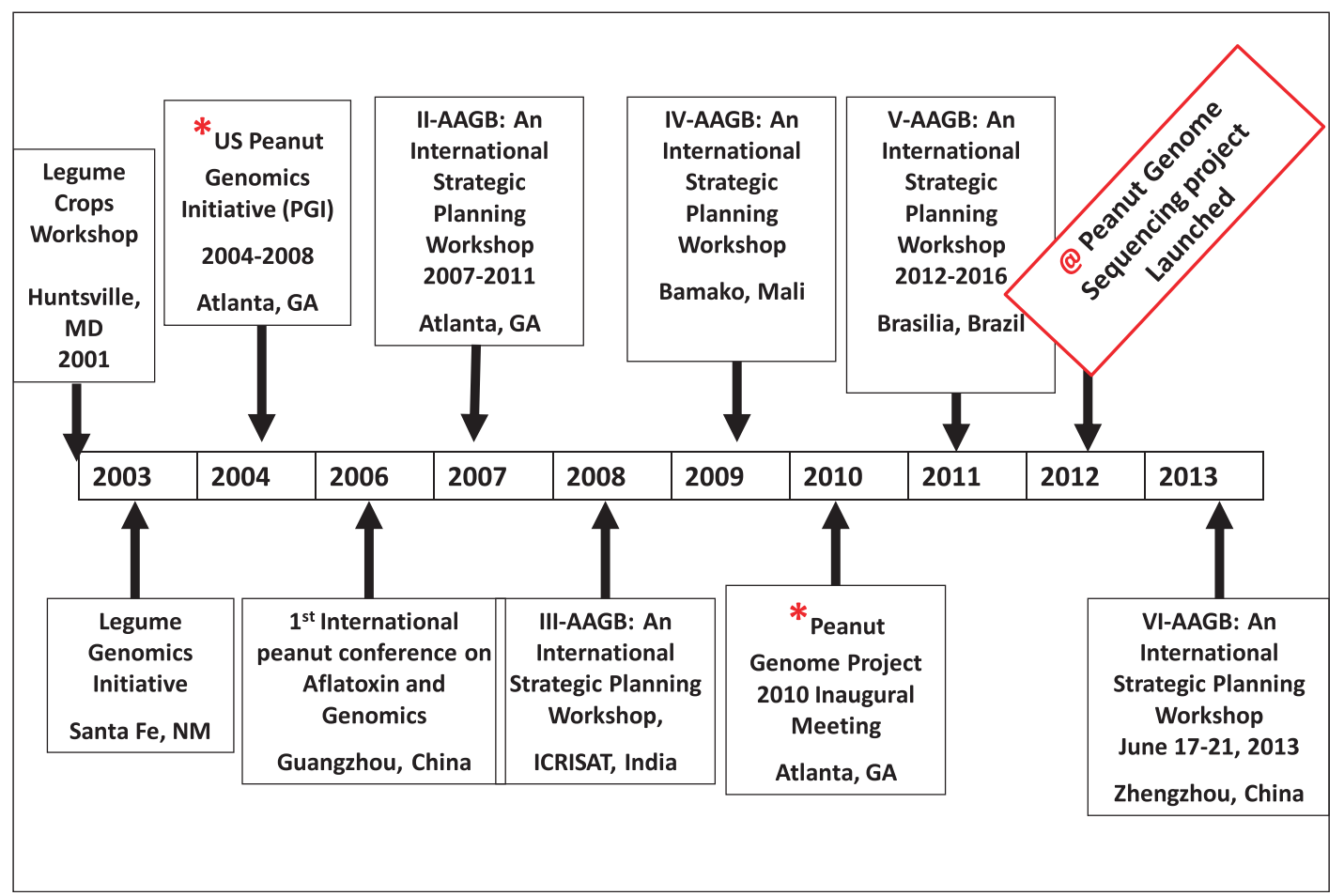

Fig. 1. Development of the International Peanut Genome Initiative (IPGI) Timeline: Advances in Arachis through Genomics and Biotechnology (AAGB) (http://www.peanutbioscience.com/peanutgenomeinitiative.html). The International Peanut Genome Initiative (IPGI) has over 135 members, in 20 countries at 79 institutions and is a committed step by the world-wide peanut research community to meet the needs of the peanut industry through genomics and biotechnology. There are two important historic events(*), 2004 Atlanta Genomics Workshop and U.S. Peanut Genomic Initiative (PGI) and the Peanut Genome Project 2010 Inaugural Meeting Atlanta, that led to the sequencing of the entire peanut genome, which was launched on 29 March, 2012.

toward bringing members of the international peanut community together to foster research collaboration on high priority issues. The International Strategic Plan for the Peanut Genome Initiative 2008-2012: Improving Crop Productivity, Protection, and Product Safety \& Quality was developed at this workshop.

Since then the tradition of excellence that was established in Guangzhou has been upheld at subsequent meetings including Advances in Arachis through Genomics \& Biotechnology (AAGB-2008) at International Crops Research Institute for the Semi-Arid Tropics (ICRISAT) in India, AAGB2009 in Mali, and AAGB-2011 in Brazil. The Peanut Foundation and the American Peanut Council on behalf of the peanut research community discussed pursuing a peanut whole genome sequencing project on 12 July 2010, at Clearwater, FL, leading to the Peanut Genome Project Inaugural Meeting in Atlanta, 8 December 2010. On 12 January 2011, at the Plant and Animal Genome Conference, San Diego, CA, the executive committee tentatively decided to sequence four peanut cultivars and 200 recombinant inbred line (RIL) progenies derived from these parents (Qin et al., 2012) in collaboration with Chinese peanut researchers. The official launch of the International
Peanut Genome Mapping Project was discussed at AAGB-2011 in Brasilia, Brazil, and the International Peanut Genomic Research Initiative - Strategic Plan for 2012-2016 was developed (Fig. 2).

Sequencing and assembly strategies were discussed and adopted on 28 March 2012 in Atlanta (Fig. 1). The Peanut Genome Consortium (PGC) is an extension of the International Peanut Genome Initiative (IPGI) which has more than 135 members representing 79 institutions from 20 countries, and is embodied by a coalition of international scientists and stakeholders engaged in the Peanut Genome Project (PGP). The chronology and progress of that effort was documented in the International Peanut Mapping Project. AAGB-2013 will be held in Zhengzhou, China, from 17-21 June 2013 and will be a forum to foster and align research activities with the International Peanut Genomic Research Initiative - Strategic Plan for 2012-2016 (Fig. 2).

\section{Recent Development in Molecular Markers}

In the early 1990s, peanut proteins were used as markers to identify genetic diversity among culti- 


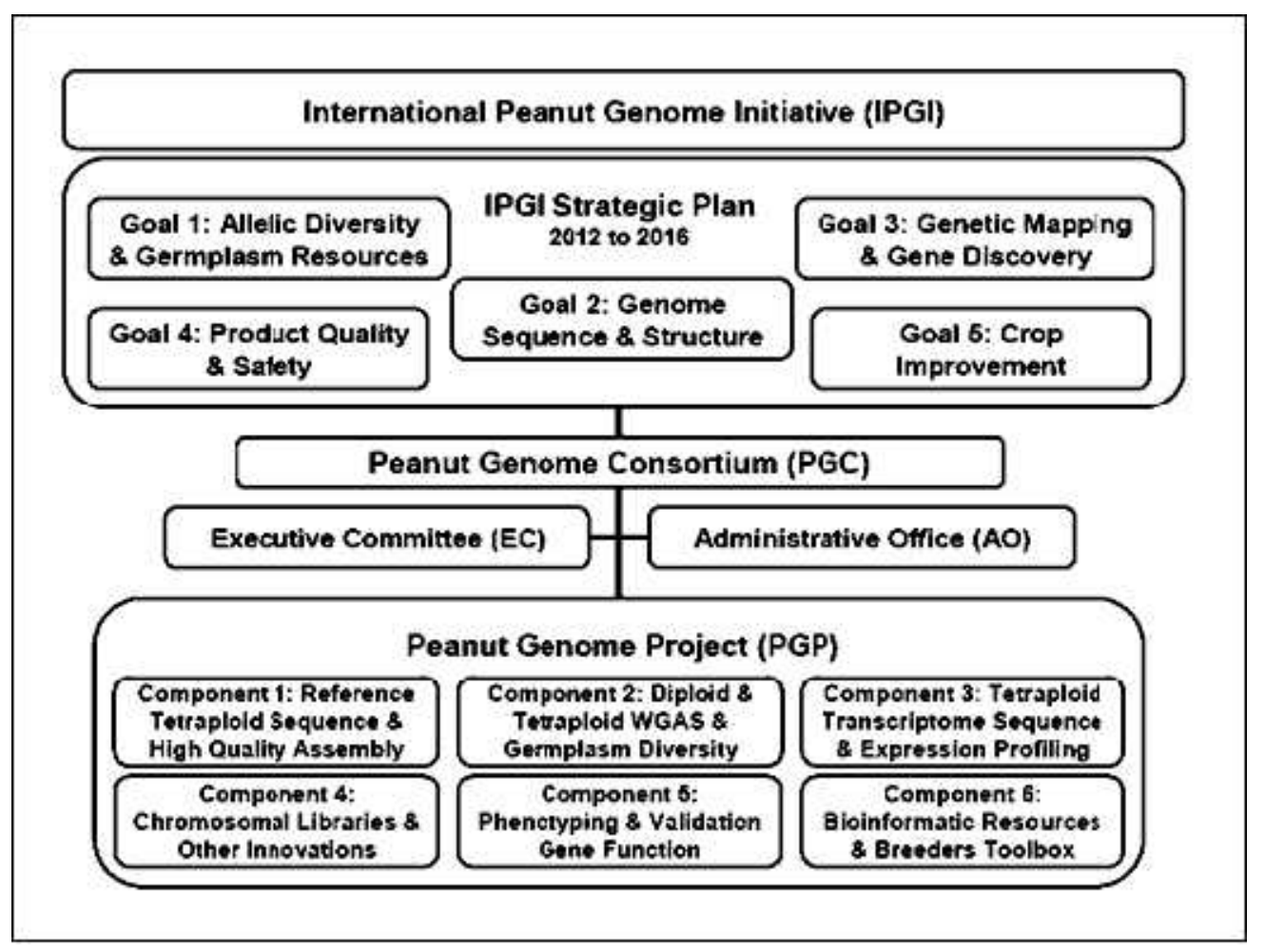

Fig. 2. Creating a Better Future through Global Food Security: The central thrust of the IPGI Strategic Plan will be implemented by the Peanut Genome Consortium (PGC), a coalition of international scientists and stakeholders engaged in the Peanut Genome Project (PGP). PGC is governed by published Policies \&Procedures. Detailed information on the International Peanut Genome Initiative, the Peanut Genome Consortium, and the Peanut Genome Project may be accessed at: http://www.peanutbioscience.com.

vated peanut and its wild diploid relatives; however, limited polymorphisms were detected (Lacks and Stalker, 1993). A greater level of polymorphism was discovered among wild species as compared to cultivated peanut (Lanham et al., 1994) suggesting domestication was a bottleneck. Advances in other marker types, such as randomly amplified polymorphic DNA (RAPD) (Halward and Stalker, 1991; Halward et al., 1992), restriction fragment length polymorphism (RFLP) (Halward and Stalker, 1991; Kochert et al., 1996; Gimenes et al., 2002; Burow et al., 2009), amplified fragment length polymorphism (AFLP) (Herselman et al., 2004), simple sequence repeat (SSR) (He et al., 2003; Gimenes et al., 2007; Cuc et al., 2008; Liang et al., 2009), sequence-related amplified polymorphism (SRAP) ( Wang et al. 2010), single strand conformational polymorphism (SSCP) (Nagy et al., 2010), and single nucleotide polymorphism (SNP) (Nagy et al., 2012), soon replaced the early exploration with proteins.

During the past two decades, much effort has been made to develop genetic and genomic tools in cultivated peanut, such as construction of BAC libraries (Yuksel and Paterson, 2005; Guimarães et al., 2008), cDNA libraries (Luo et al., 2005; Proite et al., 2007; Guo et al., 2008, 2009; Koilkonda et al., 2012), RNAseq using next generation sequencing technology (Guimaraes et al., 2012; Zhang et al., 2012) and development of DNA markers (see reviews of Feng et al., 2012; Pandey et al., 2012; Zhao et al., 2012; Varshney et al., 2013) (Table 1). Among the various molecular markers investigated to date, simple sequence repeats (SSR) have emerged as one of the preferred DNA marker system for conducting genetic and genomic studies in cultivated peanut. In recent years, a relatively large number of EST sequences have been made available in the National Center for Biotechnology Information (NCBI) public database for Arachis including the cultivated species and its wild relatives, particularly after the historic 2004 Atlanta Genomics Workshop where the ESTs were identified as a priority for marker development (Feng et al., 2012). As of December 2012, the international peanut research community had deposited 252,832 ESTs in the public NCBI EST database, and this resource has been providing the tools needed for genome-scale experiments before the whole genome sequencing project completion (Payton et al., 2009; Guo et al., 2011). To date, 15,518 SSRs have been developed by various research groups, although some are likely to be redundant (Table 1).

Several reviews have recently summarized progress in peanut genetics and genomics tool and 
Table 1. List of published SSRs and polymorphic SSRs to date in peanut.

\begin{tabular}{|c|c|c|c|c|c|c|}
\hline Marker name (prefix) & $\begin{array}{l}\text { EST/geno- } \\
\mathrm{mic} \mathrm{SSR}\end{array}$ & $\begin{array}{l}\text { Total no. } \\
\text { SSRs }\end{array}$ & $\begin{array}{l}\text { Polymor- } \\
\text { phic SSR }\end{array}$ & $\begin{array}{l}\text { Mapped } \\
\text { SSR }\end{array}$ & References & Research institution \\
\hline Ah4-xx, Ah6-xx & Genomic & 26 & 6 & 4 & Hopkins et al., 1999 & USDA-ARS, USA \\
\hline Apxx & Genomic & 7 & 2 & 1 & Palmieri et al., 2002 & $\begin{array}{l}\text { Universidade Estadual } \\
\text { Paulista, Brazil }\end{array}$ \\
\hline PMxx & Genomic & 275 & 43 & 33 & $\begin{array}{l}\text { He et al., 2003, 2005; } \\
\text { Yuan et al., } 2010\end{array}$ & Tuskegee University, USA \\
\hline PMxx & EST & 44 & 5 & 4 & He et al., 2005 & Tuskegee University, USA \\
\hline pPGPseqxx, pPGSseqxx & Genomic & 226 & 140 & 93 & Ferguson et al., 2004 & $\begin{array}{l}\text { University of Georgia/ } \\
\text { Cornell University, USA }\end{array}$ \\
\hline Ah-xx & Genomic & 67 & 12 & 7 & Moretzsohn et al., 2004 & EMBRAPA, Brazil \\
\hline Ah1xx, Ah2xx, gi-xx & Genomic & 121 & 84 & 75 & Moretzsohn et al., 2005 & EMBRAPA, Brazil \\
\hline $\begin{array}{l}\text { AS1RNxx, AS1R1xx, } \\
\text { S1MLxx, gi-xx }\end{array}$ & EST & 112 & 20 & 12 & Moretzsohn et al., 2005 & EMBRAPA, Brazil \\
\hline GAxx & Genomic & 103 & 46 & 35 & Budiman et al., 2006 & $\begin{array}{l}\text { University of Georgia/ } \\
\text { USDA-ARS, USDA }\end{array}$ \\
\hline AS1RNxx, AS1RMxx & EST & 107 & 14 & 7 & Proite et al., 2007 & $\begin{array}{l}\text { University of Brasília/ } \\
\text { EMBRAPA, Brazil }\end{array}$ \\
\hline Ahxx & Genomic & 13 & 9 & 7 & Gimenes et al., 2007 & $\begin{array}{l}\text { Universidade Estadual } \\
\text { Paulista, Brazil }\end{array}$ \\
\hline S-xx & Genomic & 123 & 45 & 4 & Wang et al., 2007 & $\begin{array}{l}\text { Shandong Peanut Research } \\
\text { Institute, China }\end{array}$ \\
\hline EM-xx, EE-xx & EST & 290 & 29 & 9 & Guo et al., 2008 & USDA-ARS, USA \\
\hline IPAHMxx & Genomic & 170 & 54 & 36 & Cuc et al., 2008 & (ICRISAT, India \\
\hline GMxx & EST & 2138 & 455 & 347 & Guo et al., 2012b & $\begin{array}{l}\text { University of Georgia/ } \\
\text { USDA-ARS, USA }\end{array}$ \\
\hline AHMxx & Genomic & 2 & 2 & 0 & Naito et al., 2008 & Ibaraki University, Japan \\
\hline AHBGSxx & EST & 35 & 2 & 0 & Moretzsohn et al., 2009 & EMBRAPA, Brazil \\
\hline ICGMxx & Genomic & 23 & 8 & 0 & Gautami et al., 2009 & ICRISAT, India \\
\hline Fxx, PDxx & EST & 33 & 4 & 0 & Song et al., 2010 & $\begin{array}{l}\text { Shandong Academy of } \\
\text { Agricultural Sciences, China }\end{array}$ \\
\hline AHSxx & EST & 3187 & 373 & 9 & $\begin{array}{l}\text { Koilkonda et al., 2012; } \\
\text { Wang et al., } 2012\end{array}$ & $\begin{array}{l}\text { Kazusa DNA Research } \\
\text { Institute, Japan } \\
\text { Tuskegee University, USA }\end{array}$ \\
\hline $\begin{array}{l}\text { GNBxx, Adxx, Aixx, } \\
\text { AHGSxx }\end{array}$ & Genomic & 2025 & 293 & 106 & Wang et al., 2012 & $\begin{array}{l}\text { Tuskegee University/UC- } \\
\text { Davis, USA }\end{array}$ \\
\hline Ah3xx & Genomic & 147 & 86 & 18 & Macedo et al., 2012 & University of Brasilia, Brazil \\
\hline HASxx & EST & 3919 & 160 & 0 & Zhang et al., 2012 & $\begin{array}{l}\text { Hebei Academy of } \\
\text { Agricultural Sciences, } \\
\text { China }\end{array}$ \\
\hline $\mathrm{XXX}$ & EST & 2325 & 584 & 214 & Guimaraes et al., 2012 & EMBRAPA, Brazil \\
\hline Total & & 15,518 & $\begin{array}{l}2,087 \\
(13.5 \%)\end{array}$ & $\begin{array}{l}807 \\
(5.2 \%)\end{array}$ & & \\
\hline
\end{tabular}

resource development (see reviews of Feng et al., 2012; Pandey et al., 2012; Zhao et al., 2012, Varshney et al., 2013). Feng et al. (2012) reported on EST progress and application (Fig. 1). Pandey et al. (2012) and Varshney et al. (2013) reported that the last five years have witnessed accelerated expansion of genomic resources such as development of molecular markers, genetic and physical maps, generation of ESTs, development of mutant resources, and functional genomics platforms that facilitate the identification of QTLs and discovery of genes associated with tolerance/resistance to abiotic and biotic stresses and agronomic traits. Molecular breeding efforts have been initiated for several traits for development of superior genotypes (Chu et al., 2011; Pasupuleti et al., 2013). In summary, 15,518 SSR markers were generated during the past decade, particularly in the last five years. It is anticipated that these informative markers will be useful to accelerate molecular genetics and breeding in cultivated peanut.

Recently, Zhao et al. (2012) compiled a list of 9274 SSRs in both cultivated and wild peanut species and integrated various research reports of 
peanut DNA polymorphism into a single platform. Zhao et al. (2012) also identified 1343 of these as detecting polymorphisms in a panel of eight cultivated peanut genotypes $(14.5 \%)$.

Next-generation sequencing technology (NGS) has provided a powerful approach for analyzing the transcriptome. Although it is still a challenge to assemble whole complex genome using NGS, the technology has facilitated cost-effective, large scale generation of ESTs. Since the reports of Pandey et al. (2012) and Zhao et al. (2012), there have been two publications of using NGS to generate EST-SSRs (Zhang et al., 2012; Guimaraes et al., 2012) (Table 1) and for SNP development (Nagy et al., 2012). Zhang et al. (2012) used Illumina HiSeq ${ }^{\mathrm{TM}} 2000$ to analyze the transcriptomes of the immature seeds of three peanut varieties with different oil contents. A total of 26.1-27.2 million paired-end reads were generated and 59,077 unigenes were assembled with an N50 of $823 \mathrm{bp}$. In addition, 3919 microsatellite markers were developed from the unigene library, and 160 PCR primers for SSR loci were used for validation. Guimaraes et al. (2012) used 454 GS FLX Titanium to generate a total of $7.4 \times 10^{5}$ raw sequence reads covering $211 \mathrm{Mbp}$ of two A-genome species (A. stenosperma and $A$. duranensis). High quality reads were assembled to 7723 contigs for $A$. stenosperma and 12,792 for A. duranensis. This data set was used to design a total of 2325 EST-SSRs, of which a subset of 584 amplified in both species and 214 were shown to be polymorphic using ePCR.

Nagy et al. (2012) reported a high-density genetic map of the diploid species $A$. duranensis based on SNPs mined from de novo EST sequence generated using Sanger and 454 GS-FLX technologies. More than one million EST sequences generated from normalized cDNA libraries of A. duranensis were assembled into 81,116 unique transcripts. In addition, 1236 EST-SNP markers were developed by mining this dataset between two A. duranensis accessions, and an additional 300 SNP markers were developed from genomic sequences representing conserved legume orthologs. Of the 1536 SNP markers, 1054 were placed on a genetic map (Nagy et al., 2012).

Markers have been developed for peanut based on Miniature Inverted-Repeat Transposable Elements (MITEs) (Shirasawa et al., 2012a) where 504 primer pairs were designed against both flanking sequences of each AhMITE1. Of the primer pairs designed, 240 and 171 generated single and double DNA bands, respectively. The double bands likely were derived from homoeologous regions in the A and $\mathrm{B}$ genomes. Of the 411 primer pairs that produced amplicons, 169 showed polymorphisms between the four tested peanut lines.

\section{Recent Advancement in Genetic Linkage Maps}

One of the major applications for molecular markers is construction of genetic linkage maps which is required for QTL studies. A more detailed linkage map of all chromosomes and with sufficient markers is necessary for QTL analysis and markerassisted breeding. Over the past few years an international effort has resulted in progress for developing genetic maps in diploid wild relatives and cultivated peanut (Pandey et al., 2012; Varshney et al., 2013).

The narrow genetic base of cultivated peanut has provided a substantial obstacle to genetic mapping using only cultivated peanuts. Therefore, the initial maps were made using crosses involving wild species. Subsequently, mapping in cultivated $\times$ cultivated crosses has advanced considerably (Table 2). The first genetic linkage map of peanut was developed using an $\mathrm{F}_{2}$ population of a cross between A-genome diploids A. stenosperma and A. cardenasii (Halward et al., 1993). The first interspecific hybrid peanut map showing introgression of wild species into the cultivated peanut was developed from $A$. hypogaea $\times A$. cardenasii using RFLP and RAPD markers (Garcia et al., 1995). A map was later developed using a synthetic tetraploid constructed from Florunner $\times$ the synthetic amphidiploid TxAG-6 $\{$ A. batizocoi $\times[$ A. cardenasii $\times A$. diogoi] $\}^{4 \times}$ (Burow et al., 2001).

The first partial linkage map for $A$. hypogaea was constructed using an $\mathrm{F}_{2}$ population (Herselman et al., 2004), which had five linkage groups with 12 AFLP markers spanning $139 \mathrm{cM}$ of the genome. The genetic maps of cultivated peanut published by Hong et al. (2008) and Varshney et al. (2009) were the first maps with reasonable numbers of markers. Hong et al. (2008) tested 1048 SSR primer pairs and mapped 131 SSR loci onto 20 linkage groups for a total length of $670 \mathrm{cM}$ on a RIL population between the cultivars Yueyou 13 and Zhenzhuhei. Varshney et al. (2009) screened 1145 SSR markers and mapped 135 loci onto 22 linkage groups spanning $1271 \mathrm{cM}$ onto a RIL population developed from two parental genotypes, TAG 24 and ICGV 86031. Later a composite map containing 175 SSR markers in 22 linkage groups was developed from three cultivated crosses (Hong et al., 2010). Another composite map was constructed with 101 SSR markers in 17 linkage groups from four populations in China (Zhang, 2011).

The SSR-based cultivated genetic map with 135 marker loci developed by Varshney et al. (2009) was then further saturated to 191 SSR loci (Ravi 
et al., 2011). Two new partial genetic maps with 56 (TAG $24 \times$ GPBD 4) and 45 (TG $26 \times$ GPBD 4) marker loci (Khedikar et al., 2010; Sarvamangala et al., 2011) were constructed covering a genetic distance of 462.24 and $657.9 \mathrm{cM}$, respectively. These two maps were then saturated with enhanced genome coverage up to 188 (1922.4 cM) and 181 (1963 cM) marker loci, respectively, along with construction of a consensus map based on these two populations segregating for foliar disease resistance with $225 \mathrm{SSR}$ loci and a total map distance of $1152.9 \mathrm{cM}$ (Sujay et al., 2012). In addition to these maps, two additional genetic maps based on RIL populations segregating for traits related to drought tolerance, namely ICGS 76 $\times$ CSMG 84-1 (119 SSR loci) and ICGS $44 \times$ ICGS 76 (82 SSR loci), were developed with genome coverage of $2208.2 \mathrm{cM}$ and $831.4 \mathrm{cM}$, respectively (Gautami et al., 2012a). Since the above three populations (TAG 24 and ICGV 86031, ICGS $76 \times$ CSMG 84-1 and ICGS $44 \times$ ICGS 76) were segregating for drought tolerance related traits, a consensus map $(2840.8 \mathrm{cM})$ with 293 SSR loci was developed. All the parental lines were cultivated genotypes, except for GPBD-4 which is predominantly cultivated with some $A$. cardenasii parentage derived through doubling the chromosome number of triploid interspecific hybrids to produce hexaploids and then selfing through several generations to recover 40-chromosome progenies (Gowda et al., 2002; Smartt et al., 1978).

More recently, Qin et al. (2012) screened a total of 4576 markers and identified 260 and 181 polymorphic markers, respectively, for the two RIL populations Tifrunner $\times$ GT-C20 (T population) and SunOleic 97R $\times$ NC94022 (S population). Individual genetic maps were constructed for $\mathrm{T}$ and $\mathrm{S}$ populations with 236 and 172 marker loci, respectively. An integrated map was then constructed with 324 marker loci covering $1352 \mathrm{cM}$ genetic distance (Qin et al., 2012). In addition to the SSRs mentioned above, Wang et al. (2012) have also used 1152 SSRs mined from 36,314 BAC-end sequences (BES) and constructed a genetic map with a total of 318 markers covering $1674.4 \mathrm{cM}$ in a single mapping population. For the creation of the highest density map of a single population of cultivated peanut to date, Shirasawa et al. (2012b) reported the use of in silico analysis of DNA sequence data from the parental lines, which increased the efficiency of polymorphic marker development by more than three-fold. In total, 926 $(34.2 \%)$ of 2702 markers showed polymorphisms between parental lines of the mapping population. Linkage analysis of the 926 markers along with 253 polymorphic markers selected from 4449 published markers generated 21 linkage groups covering $2166.4 \mathrm{cM}$ with 1114 loci (Shirasawa et al., 2012b).

In spite of these efforts, development of composite maps based on two or three individual maps has not sufficiently integrated genetic information across studies. An international effort was initiated to place the maximum number of markers on the same genetic map through integrating markers from all individual genetic maps published to date. Marker information from one backcross (BC) population (Foncéka et al., 2009) was also included in the development of a reference consensus map along with other 10 individual genetic maps developed from RIL populations. The first international reference consensus genetic map was constructed with 897 marker loci. These 897 marker loci (895 SSRs and 2 CAPS) could be mapped on 20 linkage groups spanning a total map distance of $3607.97 \mathrm{cM}$ with an average map density of $3.94 \mathrm{cM}$. More interestingly, this reference consensus genetic map was divided into 203 sets of $20 \mathrm{cM}$ bins, each which carry one to 20 loci with an average of four marker loci per bin. Furthermore, soon after the first dense consensus map published by Gautami et al. (2012b), another joint international research effort has resulted in a much improved consensus genetic map based on 16 mapping populations. The mapping information from five new genetic maps were utilized for improvement of the earlier consensus map from 897 marker loci to 3693 marker loci spanning $2651 \mathrm{cM}$ of the genome and 20 linkage groups (Shirasawa et al., 2013). These dense consensus maps will have greater impact on peanut genetic studies and improvement because of the potential applications such as aligning genetic and physical maps, QTL analysis, genetic background effect on QTL expression, comparative mapping, and other genetic and molecular breeding research in peanut.

\section{Summary}

Lack of sufficient molecular markers, genetic linkage maps, and comparative genome sequences for peanut severely hampers peanut genetic improvement efforts as well as marker-trait association studies and functional validation. The international peanut community has come a long way toward achieving significant accomplishments in marker and genetic map development. As SSRs are the markers of choice for many genetic mapping studies, the mapped SSR loci are useful not only for trait-gene/marker association 

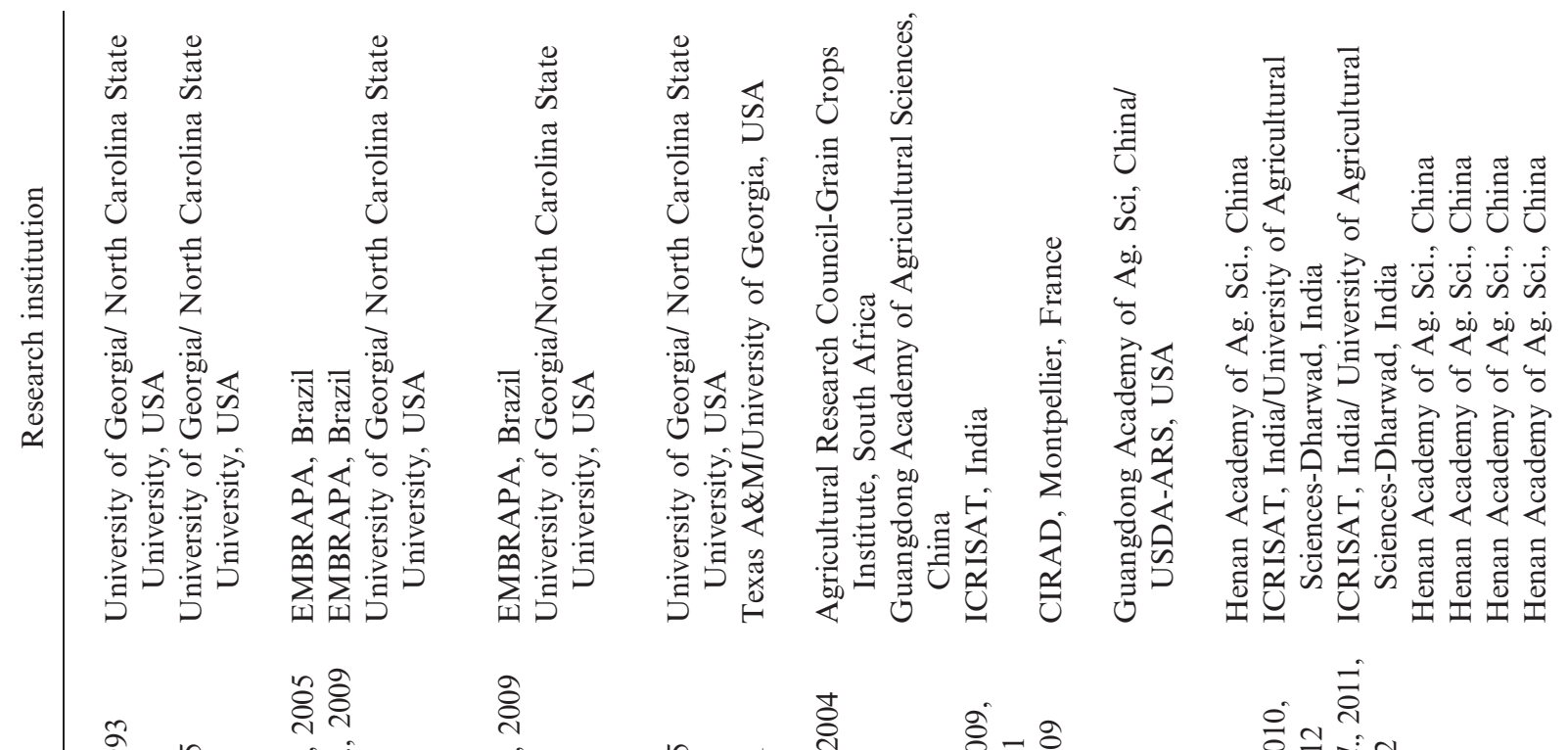

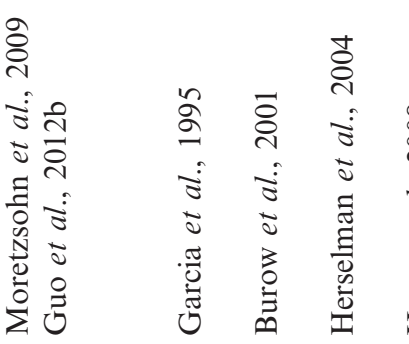

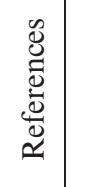

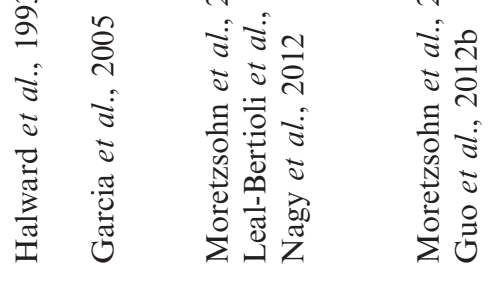

嗼 :

퓽

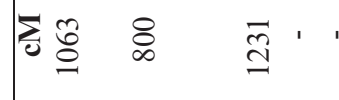

ำ

(1)

离

$=\quad=00 \quad$

齐

$\because=\pi$ ก

¿ $\overline{0}$

ले

离

$\stackrel{\infty}{0}$

(2)

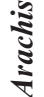

$\min _{\min } \frac{0}{2}$

II IN

式 式

볼

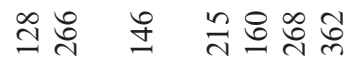

?

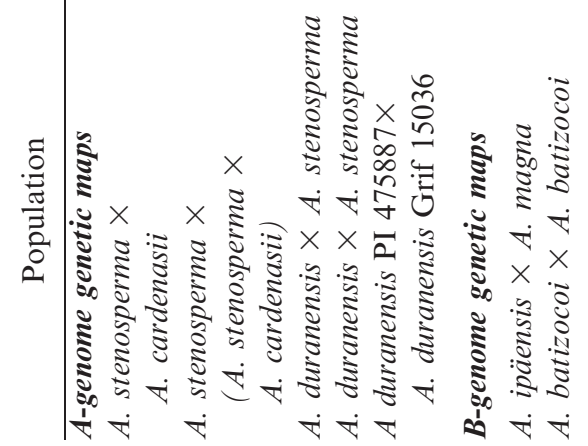

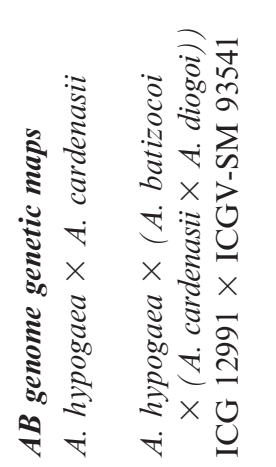

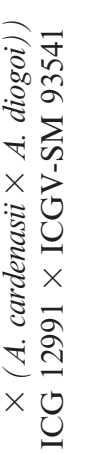

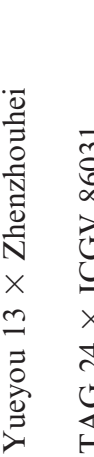




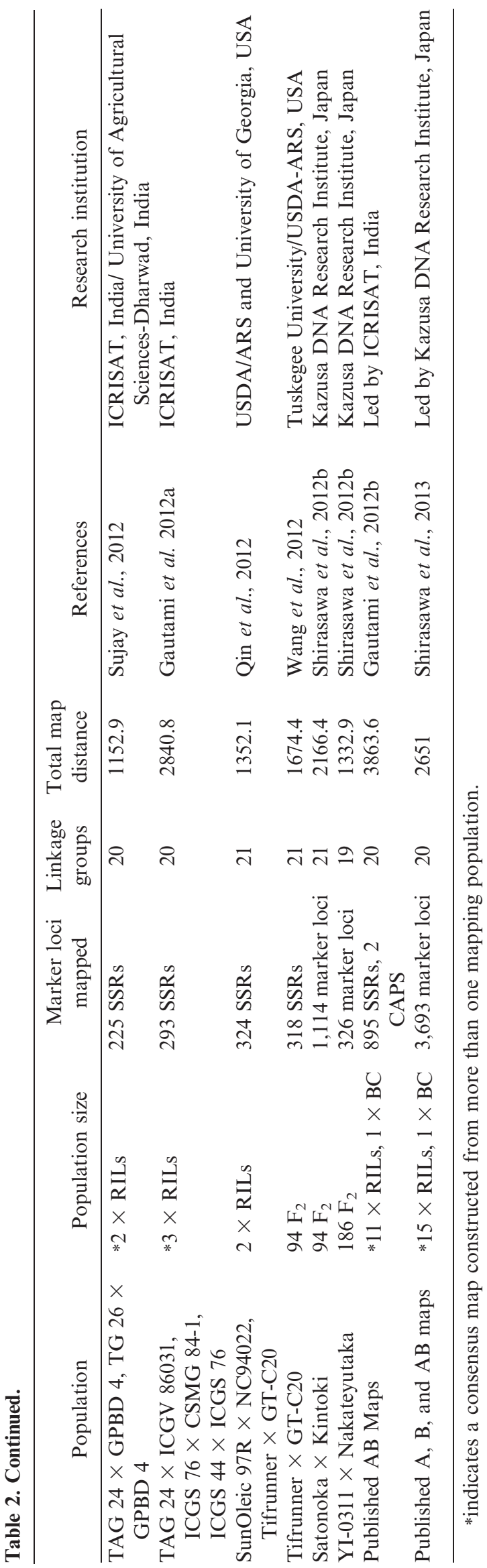

and QTL analysis but also for allocating associated QTLs to map-based cloning of functional gene(s) where numerous ESTs (that could be potential candidate genes) are currently placed on the map. With the development of the next generation SNP markers and completion of whole genome sequences for cultivated peanut and wild relatives anticipated in the near future, the "Orphan Legume Genome Whose Time Has Come" will soon be realized, as reported in this American Peanut Research and Education Society 2012 symposium. One demonstration of the power of marker-assisted breeding in peanut is the conversion of peanut cultivar 'Tifguard' (Holbrook et al., 2008) into 'high oleic Tifguard' in 26 months (Chu et al., 2011). Additionally, the collaborative and coordinated efforts of the international peanut community since 2004 have contributed to development of large-scale genomic resources and tools to tap into the rich resource of germplasm collections for improvement of peanut for sustainable production, quality, pest resistance and water use efficiency. With the establishment of NGS technology platforms and cost reduction for DNA sequencing, whole genome sequencing and re-sequencing will become a routine task for crop research and improvement in the near future (Varshney and May, 2012). The main issue will be in analyzing data and translating the information to peanut breeding and improvement through discovery of genes governing and molecular markers associated with the important traits.

\section{Acknowledgements}

We would like to express our appreciation to U.S. Peanut Industries and the leadership of the Peanut Foundation and American Peanut Council, particularly to Howard Valentine for his efforts to make this PGI and PGC a reality. We also thank Dr. Howard Shapiro of Mars Inc. for initiating discussions with BGI and opening the way for collaborations with Chinese researchers. We are grateful for the financial support from USDAARS, Peanut Foundation, Georgia Peanut Commission and U.S. National Peanut Board, Mars Inc., Chinese genome collaborators (Henan Academy of Ag. Sci., Oil Crops Research Institute of Chinese Academy of Ag. Sci., and Hi-Tech Center of Shandong Academy of Ag. Sci.), National Fund of the Basic and Strategic Research in Agriculture (NFBSRA) of the Indian Council of Agriculture Research (ICAR), and the Generation Challenge Programme of CGIAR. 


\section{Literature Cited}

Boerma, H.R., J. St. John, and J.Y. Molen. 2001. U.S. Legume Crops Genomics Workshop 30-31 July 2001, Hunt Valley, MD. White Paper. 29 pp.

Budiman, M.A., J.I.T. Jones, R.W. Citek, U. Warek, J.A. Bedell, and S.J. Knapp. 2006. Methylationfiltered and shotgun genomic sequences for diploid and tetraploid peanut taxa. http://www. ncbi.nlm.nih.gov/nucgss.

Burow, M.D., C.E. Simpson, M.W. Faries, J.L. Starr, and A.H. Paterson. 2009. Molecular biogeographic study of recently described B- and A-genome Arachis species, also providing new insights into the origins of cultivated peanut. Genome 52:107-119.

Burow, M.D., C.E. Simpson, J.L. Starr, and A.H. Paterson. 2001. Transmission genetics of chromatin from a synthetic amphiploid in cultivated peanut (A. hypogaea $\mathrm{L}$.): Broadening the gene pool of a monophyletic polyploid species. Genetics1 59:823-837.

Chu, Y., C.L. Wu, C.C. Holbrook, B.L. Tillman, G. Person, and P. Ozias-Akins. 2011. Marker-assisted selection to pyramid nematode resistance and the high oleic trait in peanut. Plant Genome 4:110-117.

Cuc, L.M., E.S. Mace, J.H. Crouch, V.D. Quang, T.D. Long, and R.K. Varshney. 2008. Isolation and characterization of novel microsatellite markers and their application for diversity assessment in cultivated groundnut (Arachis hypogaea). BMC Plant Biol. 8:55.

Feng, S., X. Wang, X. Zhang, P.M. Dang, C.C. Holbrook, A.K. Culbreath, Y. Wu, and B.Z. Guo. 2012. Peanut (Arachis hypogaea) expressed sequence tag (EST) project: progress and application. Comparative and Functional Genomics 2012:373768, 9 pp. DOI:10.1155/2012/373768

Ferguson, M.E., M.D. Burow, S.R. Schultze, P.J. Bramel, A.H. Paterson, S. Kresovich, and S. Mitchell. 2004. Microsatellite identification and characterization in peanut (A. hypogaea L.). Theor. Appl. Genet. 108:1064-1070.

Foncéka, D., T. Hodo-Abalo, R. Rivallan, I. Faye, M.N. Sall, O. Ndoye, A.P. Fávero, D.J. Bertioli, J.C. Glaszmann, B. Courtois, and J.F. Rami. 2009. Genetic mapping of wild introgressions into cultivated peanut: a way toward enlarging the genetic basis of a recent allotetraploid. BMC Plant Biol. 9:103.

Garcia, G.M., H.T. Stalker, and G. Kochert. 1995. Introgression analysis of an interspecific hybrid population in peanuts (Arachis hypogaea L.) using RFLP and RAPD markers. Genome 38:166-176.

Garcia, G.M., H.T. Stalker, E. Schroeder, J.H. Lyerly, and G. Kochert. 2005. A RAPD-based linkage map of peanut based on a backcross population between the two diploid species Arachis stenosperma and A. cardenasii. Peanut Sci. 32:1-8.

Gautami, B., K. Ravi, N.M. Lakshmi, D.A. Hoisington, and R.K. Varshney. 2009. Novel set of groundnut SSRs for genetic diversity and interspecific transferability. Int. Jour. Integr. Biology 7:100-106.

Gautami, B., M.K. Pandey, V. Vadez, S.N. Nigam, P. Ratnakumar, L. Krishnamurthy, T. Radhakrishnan, M.V.C. Gowda, M.L. Narasu, D.A. Hoisington, S.J. Knapp, and R.K. Varshney. 2012a. QTL analysis and consensus genetic map for drought tolerance traits based on three RIL populations of cultivated groundnut (Arachis hypogaea L.). Mol. Breed. 32:757-772.

Gautami, B., D. Fonceka, M.K. Pandey, M.C. Morezsohn, V. Sujay, H. Qin, Y. Hong, I. Faye, X. Chen, A. Bhanuprakash, T.M. Shah, M.V.C. Gowda, S.N. Nigam, X. Liang, D.A. Hoisington, B. Guo, D.J. Bertioli, J.F. Rami, and R.K. Varshney. 2012b. An international reference consensus genetic map with 897 marker loci based on 11 mapping populations for tetraploid groundnut (Arachis hypogaea L.). PLoS ONE 7:e41213.

Gepts, P., W.D. Beavis, E.C. Brummer, R.C. Shoemaker, H.T. Stalker, N.F. Weeden, and N.D. Young. 2005. Legumes as a model plant family. Genomics for food and feed report of the Cross-Legume Advances through Genomics Conference. Plant Physiology 137:1228-1235.

Gimenes, M.A., A.A. Hoshino, A.V. Barbosa, D.A. Palmieri, and C.R. Lopes. 2007. Characterization and transferability of microsatellite markers of the cultivated peanut (Arachis hypogaea). BMC Plant Biol. 7:9.
Gimenes, M.A., C.R. Lopes, L. Galgaro, J.F. Valls, and G. Kochert. 2002. RFLP analysis of genetic variation in species of section Arachis, genus Arachis (Leguminosae). Euphytica 123:421-429.

Gowda, M.V.C., B.N. Motagi, G.K. Naidu, S.B. Diddimani, and R. Sheshagiri. 2002. GPBD 4: A Spanish bunch groundnut genotype resistant to rust and late leaf spot. Int. Arachis Newsletter 22:29-32.

Guimarães PM, O. Garsmeur, K. Proite, S.C.M. Leal-Bertioli, G. Seijo, C. Chaine, D.J. Bertioli, and A. D'Hont. 2008. BAC libraries construction from the ancestral diploid genomes of the allotetraploid cultivated peanut. BMC Plant Biol. 8:14.

Guimaraes, P.M., A.C.M. Brasileiro, C.V. Morgante, A.C.Q.M. Martins, G. Pappas, O.B. Silva, Jr., R. Togawa, S.C.M. Leal-Bertioli, A.C.G. Araújo, M.C.M. Moretzsohn, and D.J. Bertioli. 2012. Global transcriptome analysis of two wild relatives of peanut under drought and fungi infection. BMC Genomics 13:387. doi:10.1186/1471-216413-387.

Guo, B.Z., X. Chen, P. Dang, B.T. Scully, X. Liang, C.C. Holbrook, J. Yu, and A.K. Culbreath. 2008. Peanut gene expression profiling in developing seeds at different reproduction stages during Aspergillus parasiticus infection. BMC Devel. Biology 8:12. doi:10.1186/1471-213X-8-12.

Guo, B.Z., X. Chen, Y. Hong, X. Liang, P. Dang, T. Brenneman, C.C. Holbrook, and A.K. Culbreath. 2009. Analysis of gene expression profiles in leaf tissues of cultivated peanuts and development of EST-SSR markers and gene discovery. Int. Jour. Plant Genomics 2009:715605. 14 pp. doi:10.1155/2009/715605.

Guo, B.Z., C.Y. Chen, Y. Chu, C.C. Holbrook, P. Ozias-Akins, and H.T. Stalker. 2012a. Advances in genetics and genomics for sustainable peanut production, pp. 341-367. In: N. Benkeblia (ed.), Sustainable Agriculture and New Biotechnologies, CRC Press, Boca Raton, FL.

Guo, B.Z., N.D. Fedorova, X. Chen, C.H. Wan, W. Wang, W.C Nierman, D. Bhatnagar, and J. Yu. 2011. Gene expression profiling and identification of resistance genes to Aspergillus flavus infection in peanut through EST and microarray startegies. Toxins 3:737-753.

Guo, Y., S. Khanal, S. Tang, J.E. Bowers, A.F. Heesacker, N. Khalilian, E.D. Nagy, D. Zhang, C.A. Taylor, H.T. Stalker, P. Ozias-Akins, and S.J. Knapp. 2012b. Comparative mapping in intraspecific populations uncovers a high degree of macrosynteny between A- and B- genome diploid species of peanut. BMC Genomics 13:608.

Halward, T. and H.T. Stalker. 1991. Genetic variation detectable with molecular markers among unadapted germplasm resources of cultivated peanut and related wild species. Genome 34:1013-20.

Halward, T., T. Stalker, E. LaRue, and G. Kochert. 1992. Use of single-primer DNA amplifications in genetic studies of peanut (Arachis hypogaea L.). Plant Mol. Biol. 18:315-325.

Halward, T.M., H.T. Stalker, and G. Kochert. 1993. Development of an RFLP linkage map in diploid peanut species. Theor. Appl. Genet. 87:379-384.

He, G.H., R. Meng, M. Newman, G. Gao, R.N. Pittman, and C.S. Prakash. 2003. Microsatellites as DNA markers in cultivated peanut (Arachis hypogaea L.). BMC Plant Biol 3:3.

He, G., R. Meng, H. Gao, B. Guo, G. Gao, M. Newman, R. Pittman, and C.S. Prakash. 2005. Simple sequence repeat markers for botanical varieties of cultivated peanut (Arachis hypogaea L.) Euphytica 142:131-136.

Herselman, L.R., F.M. Thwaites, B. Kimmins, P.J.A. Courtois, V.D. Merwe, and S.E. Seal. 2004. Identification and mapping of AFLP markers linked to peanut (Arachis hypogaea L.) resistance to the aphid vector of groundnut rosette disease. Theor. Appl. Genet. 109:1426-1433

Holbrook, C.C., P. Timper, A. Culbreath, and C.K. Kvien. 2008. Registration of 'Tifguard' peanut. Jour. Plant Reg. 2:92-94.

Hong, Y.-B., X.-Q. Liang, X.-P. Chen, H.-Y. Liu, G.-Y. Zhou, S.-X. Li, and S.-J. Wen. 2008. Construction of genetic linkage map based on SSR markers in peanut (Arachis hypogaea L.). Agric. Sci. in China 7:915-921.

Hong, Y., X. Chen, X. Liang, H. Liu, G. Zhou, S. Li, S. Wen, C.C. Holbrook, and B. Guo. 2010. A SSR-based composite genetic linkage map for the cultivated peanut (Arachis hypogaea L.) genome. BMC Plant Biology 10:17. doi:10.1186/1471-2229-10-17.

Hopkins, M.S., A.M. Casa, T. Wang, S.E. Mitchell, R.E. Dean, G.D. Kochert, and S. Kresovich. 1999. Discovery and characterization 
of polymorphic simple sequence repeats (SSRs) in peanut. Crop Sci. 39:1243-1247.

Khedikar, Y.P., M.V.C. Gowda, C. Sarvamangala, K.V. Patgar, H.D. Upadhyaya, and R.K. Varshney. 2010. A QTL study on late leaf spot and rust revealed one major QTL for molecular breeding for rust resistance in groundnut (Arachis hypogaea L.). Theor. Appl. Genet. 121:971-984

Kochert, G., H.T. Stalker, M. Gimenes, L. Galgaro, C.R. Lopes, and K. Moore. 1996. RFLP and cytogenetic evidence on the origin and evolution of allotetraploid domesticated peanut, Arachis hypogaea (Leguminosae). Amer. Jour. Bot. 83:1282-1291.

Koilkonda, P., S. Sato, S. Tabata, K. Shirasawa, A. Watanabe, T. Wada, Y. Kishida, H. Tsuruoka, T. Fujishiro, M. Yamada, M. Kohara, S. Suzuki, M. Hasegawa, H. Kiyoshima, and S. Isobe. 2012. Large-scale development of expressed sequence tag-derived simple sequence repeat markers and diversity analysis in Arachis spp. Mol. Breed. 30:125-138. DOI 10.1007/s11032-011-9604-8.

Lacks, G.D. and H.T. Stalker. 1993. Isozyme analyses of Arachis species and interspecific hybrids. Peanut Sci. 20:76-81.

Lanham, P.G., B.P. Foster, and P. McNicol. 1994. Seed storage protein variation in Arachis species. Genome 37:487-96.

Leal-Bertioli, S.C.M., A.C. José, D.M. Alves-Freitas, M.C. Moretzsohn, P.M. Guimarães, S. Nielen, B.S. Vidigal, R.W. Pereira, J. Pike, A.P. Fávero, M. Parniske, R.K. Varshney, and D.J. Bertioli. 2009. Identification of candidate genome regions controlling disease resistance in Arachis. BMC Plant Biol. 9:112.

Liang, X., X. Chen, Y. Hong, H. Liu, G. Zhou, S. Li, and B. Guo. 2009. Utility of EST-derived SSR in cultivated peanut (Arachis hypogaea L.) and Arachis wild species. BMC Plant Biol. 9:35.

Luo, M., P. Dang, B. Guo, G. He, C.C. Holbrook, M.G. Bausher, and R.D. Lee. 2005. Generation of expressed sequence tags (ESTs) for gene discovery and marker development in cultivated peanut. Crop Sci. 45:346-353.

Macedo, S.E., M.C. Moretzsohn, S.C.M. Leal-Bertioli, D.M.T. Alves, E.G. Gouvea, V.C.R. Azevedo, and D.J. Bertioli. 2012. Development and characterization of highly polymorphic long TC repeat microsatellite markers for genetic analysis of peanut. BMC Res. Notes 5:86.

Moretzsohn, M.C., A.V.G. Barbosa, D.M.T. Alves-Freitas, C. Teixeira, and S.C. Leal-Bertioli. 2009. A linkage map for the B-genome of Arachis (Fabaceae) and its synteny to the A-genome. BMC Plant Biol. 9:40.

Moretzsohn, M.C., M.S. Hopkins, S.E. Mitchell, S. Kresovich, J.F.M. Valls, and M.E. Ferreira. 2004. Genetic diversity of peanut (Arachis hypogaea L.) and its wild relatives based on the analysis of hyper variable regions of the genome. BMC Plant Biol. 4:11.

Moretzsohn, M.C., L. Leoi, K. Proite, P.M. Guimaras, S.C.M. LealBertioli, M.A. Gimenes, W.S. Martins, J.F.M. Valls, D. Grattapaglia, and D.J. Bertioli. 2005. A microsatellite-based, gene-rich linkage map for the AA genome of Arachis (Fabaceae). Theor. Appl. Genet. 111:1060-1071.

Nagy, E.D., Y. Guo, S. Tang, J.E. Bowers, R.A. Okashah, C.A Taylor, D. Zhang, S. Khanal, A.F. Heesacker, N. Khalilian, A.D. Farmer, N. Carrasquilla-Garcia, R.V. Penmetsa, D. Cook, H.T. Stalker, N. Nielsen, P. Ozias-Akins, and S.J. Knapp. 2012. A highdensity genetic map of Arachis duranensis, a diploid ancestor of cultivated peanut. BMC Genomics 13:469. doi:10.1186/1471-216413-469.

Nagy, E., Y. Chu, Y. Guo, S. Khanal, S. Tang, Y. Li, W. Dong, P. Timper, C. Taylor, P. Ozias-Akins, C. Holbrook, V. Beilinson, N. Nielsen, T. Stalker, and S. Knapp. 2010. Recombination is suppressed in an alien introgression in peanut harboring Rma, a dominant root-knot nematode resistance gene. Mol. Breed. 26:357-370.

Naito, Y., S. Suzuki, Y. Iwata, and T. Kuboyama. 2008. Genetic diversity and relationship analysis of peanut germplasm using SSR markers. Breed. Sci. 58:293-300.

Nature Editorial. 2010. How to feed a hungry world. Nature 466:531-532. (http://www.nature.com/nature/journal/v466/n7306/ pdf/466531a.pdf)

Palmieri, D.A., A.A. Hoshino, J.P. Bravo, C.R. Lopes, and M.A. Gimenes. 2002. Isolation and characterization of microsatellite loci from the forage species Arachis pintoi (genus Arachis). Mol. Ecol. Notes 2:551-553.
Pandey, M.K., E. Monyo, P. Ozias-Akins, X. Liang, P. Guimarães, S.N. Nigam, H.D. Upadhyaya, P. Janila, X. Zhang, B. Guo, D.R. Cook, D.J. Bertioli, R. Michelmore, and R.K. Varshney. 2012. Advances in Arachis genomics for peanut improvement. Biotech Adv. 30:639-651.

Pasupuleti, J., S.N. Nigam, M.K. Pandey, P. Nagesh, and R.K. Varshney. 2013. Groundnut improvement: use of genetic and genomic tools. Front. Plant Sci. 4:23. doi: 10.3389/fpls.2013.00023

Payton, P., K.R. Kottapalli, D. Rowland, W. Faircloth, B. Guo, M. Burow, N. Puppala, and M. Gallo. 2009. Gene expression profiling in peanut using high density oligonucleotide microarrays. BMC Genomics 10:265. doi:10.1186/1471-2164-10-265.

Proite, K., S.C. Leal-Bertioli, D.J. Bertioli, M.C. Moretzsohn, F.R. da Silva, N.F. Martins, and P.M. Guimarães. 2007. ESTs from a wild Arachis species for gene discovery and marker development. BMC Plant Biol. 7:7.

Qin, H., S. Feng, C. Chen, Y. Guo, S. Knapp, A. Culbreath, G. He, M.L. Wang, X. Zhang, C.C. Holbrook, P. Ozias-Akins, and B.Z. Guo. 2012. An integrated genetic linkage map of cultivated peanut (Arachis hypogaea L.) constructed from two RIL populations. Theor. Appl. Genet. 124:653-664.

Ravi, K., V. Vadez, S. Isobe, R.R. Mir, Y. Guo, S.N. Nigam, M.V.C. Gowda, T. Radhakrishnan, D.J. Bertioli, S.J. Knapp, and R.K. Varshney. 2011. Identification of several small-effect main QTLs and larg number of epistatic QTLs for drought tolerance in groundnut (Arachis hypogaea L.). Theor. Appl. Genet. 122: $1119-1132$.

Sarvamangala, C., M.V.C. Gowda, and R.K. Varshney. 2011. Identification of quantitative trait loci for protein content, oil content and oil quality for groundnut (Arachis hypogaea L.). Field Crops Res. 122:49-59.

Shirasawa, K., H. Hirakawa, S. Tabata, M. Hasegawa, H. Kiyoshima, S. Suzuki, S. Sasamoto, A. Watanabe, T. Fujishiro, and S. Isobe. 2012a. Characterization of active miniature inverted-repeat transposable elements in the peanut genome. Theor. Appl. Genet. 124:1429-1438.

Shirasawa, K., P. Koilkonda, K. Aoki, H. Hirakawa, S. Tabata, M. Watanabe, M. Hasegawa, H. Kiyoshima, S. Suzuki, C. Kuwata, Y. Naito, T. Kuboyama, A. Nakaya, S. Sasamoto, A. Watanabe, M. Kato, K. Kawashima, Y. Kishida, M. Kohara, A. Kurabayashi, C. Takahashi, H. Tsuruoka, T. Wada, and S. Isobe. 2012b. In silico polymorphism analysis for the development of simple sequence repeat and transposon markers and construction of linkage map in cultivated peanut. BMC Plant Biol. 12:80.

Shirasawa, K., D.J. Bertioli, R.K. Varshney, M.C. Moretzsohn, S.C.M. Leal-Bertioli, M. Thudi, M.K. Pandey, J.-F. Rami, D. Fonceka, M.V.C. Gowda, H. Qin, B. Guo, Y. Hong, X. Liang, H. Hirakawa, S. Tabata, and S. Isobe. 2013. Integrated consensus map of cultivated peanut and wild relatives reveals structures of the $\mathrm{A}$ and $\mathrm{B}$ genomes of Arachis and divergence of the legume genomes. DNA Research 1-12. doi:10.1093/dnares/dss042

Smartt, J., W.C. Gregory, and M.P. Gregory. 1978. The genomes of Arachis hypogaea. 1. Cytogenetic studies of putative genome donors. Euphytica 27:665-675.

Song, G.Q., M.J. Li, H. Xiao, X.J. Wang, R.H. Tang, H. Xia, C.Z. Zhao, and Y.P. Bi. 2010. EST sequencing and SSR marker development from cultivated peanut (Arachis hypogaea L.). Electronic Jour. Biotechnol. 13(3):1-9. DOI:10.2225/vol13-issue3fulltext-10.

Sujay, V., M.V.C. Gowda, M.K. Pandey, R.S. Bhat, Y.P. Khedikar, H.L. Nadaf, B. Gautami, C. Sarvamangala, S. Lingaraju, T. Radhakrishan, S.J. Knapp, and R.K. Varshney. 2012. QTL analysis and construction of consensus genetic map for foliar diseases resistance based on two RIL populations in cultivated groundnut (Arachis hypogaea L.). Mol. Breed. 32:773-788.

Valentine, H., E. Grabau, P. Ozias-Akins, V. Nwosu, R. Wilson, M. Gallo, K. Chenault, H.T. Stalker, A.W. Weissinger, P. Donahue, M. Lamb, and E. Murphy. 2006. Biotech Peanut White Paper: Benefits and Issues. American Peanut Council, Alexandria, VA. $14 \mathrm{pp}$.

Varshney, R.K., D.J. Bertioli, M.C. Moretzsohn, V. Vadez, L. Krishnamurthy, R. Aruna, S.N. Nigam, B.J. Moss, K. Seetha, K. Ravi, G. He, S.J. Knapp, and D.A. Hoisington. 2009. The first SSR-based genetic linkage map for cultivated groundnut (Arachis hypogaea L.). Theor. Appl. Genet. 118:729-739. 
Varshney, R.K. and G.D. May. 2012. Next-generation sequencing technologies: opportunities and obligations in plant genomics. Brief Funct Genomics 11:1-2

Varshney, R.K., S.M. Mohan, P.M. Gaur, N.V.P.R. Ganga Rao, M.K. Pandey, A. Bohra, S.L. Sawargaonkar, A. Gorantla, P.K Kimurto, P. Janila, K.B. Saxena, A. Fikre, M. Sharma, A. Rathore, A. Pratap, S. Tripathi, S. Datta, S.K. Chaturvedi, N. Mallikarjuna, G. Anuradha, A. Babbar, A.K. Chaudhary, M.B. Mhase, C. Bharadwaj, D.M. Mannur, P.N. Harer, B. Guo, X. Liang, N. Nadarajan, and C.L.L. Gowda. 2013. Achievements and prospects of genomics-assisted breeding in three legume crops of the semi-arid tropics. Biotech. Adv. doi: 10.1016/j.biotechadv. 2013.01.001.

Wang, C.T., X.D. Yang, D.X. Chen, S.L. Yu, G.Z. Liu, Y.Y. Tang, and J.Z. Xu. 2007. Isolation of simple sequence repeats from groundnut. Electronic Jour. Biotechnol. 10:3.

Wang, H., R.V. Penmetsa, M. Yuan, L. Gong, Y. Zhao, B. Guo, A.D. Farmer, B.D. Rosen, J. Gao, S. Isobe, D.J. Bertioli, R.K. Varshney, D.R. Cook, and G. He. 2012. Development and characterization of BAC-end sequence derived SSRs, and their incorporation into a new higher density genetic map for cultivated peanut (Arachis hypogaea L.). BMC Plant Biol 12:10.

Wang, Q., X.Y. Zhang, F.S. Tang, W.Z. Dong, and J. Xu. 2010. Construction of genetic linkage map of peanut (Arachis hypogaea L.) based on SRAP markers. Chinese Jour. Oil Crop Sci 32:374-378.
Wilson, R.F., H.T. Stalker, and C.E. Brummer. 2004. Genomics for Legume Crops. Amer. Oil Chemical Soc. Press, Champaign, IL. 362 pp.

Wilson, R.F. 2006a. National Strategic Plan for the Peanut Genome Initiative 2004-2008. vers. 2.4. USDA, Beltsville, MD. 19 pp.

Wilson, R.F. 2006b. National Program Action Plan for the Peanut Genome Initiative: Application of Plant Genomics to Mitigate Peanut Allergy, vers. 2.4. USDA, Beltsville, MD. 25 pp.

Yuan, M., L. Gong, R. Meng, S. Li, P. Dang, B.Z. Guo, and G. He. 2010. Development of trinucleotide (GGC)n SSR markers in peanut (Arachis hypogaea L.). Electronic Journal of Biotechnology 13:6. http://dx.doi.org/10.2225/vol13-issue6-fulltext-6.

Yuksel, B. and A.H. Paterson. 2005. Construction and characterization of a peanut HindIII BAC library. Theor. Appl. Genet. 111:630-639.

Zhang, X.Y. 2011. Inheritance of main traits related to yield, quality, disease resistance, and QTLs mapping in peanut (Arachis hypogaed L.). Ph. D. Dissertation of Zhejiang University (in Chinese with English abstract).

Zhang, J., S. Liang, J. Duan, J. Wang, S. Chen, Z. Cheng, Q. Zhang, X. Liang, and Y. Li, et al. 2012. De novo assembly and Characterisation of the Transcriptome during seed development, and generation of genic-SSR markers in Peanut (Arachis hypogaea L.). BMC Genomics 13:90.

Zhao, Y., C.S. Prakash, and G. He. 2012. Characterization and compilation of polymorphic simple sequence repeat (SSR) markers of peanut from public database. BMC Res. Notes 5:362. 